\title{
Anti-metastatic effect of curcumin analog pentagamaboronon-0-fructose (PGB-0-F) against 4T1 breast cancer cells
}

\author{
Yogi Ertanto ${ }^{1,2}$, Rohmad Yudi Utomo ${ }^{3}$, Riris Istighfari Jenie ${ }^{3,4}$, Ratna Asmah Susidarti ${ }^{3,4}$, and Edy Meiyanto ${ }^{3,4,{ }^{*}}$ \\ ${ }^{1}$ Biotechnology Program, Graduate School of Universitas Gadjah Mada, Jalan Teknika Utara, Sleman, Yogyakarta 55281, Indonesia \\ ${ }^{2}$ Army Medical Center, Jalan Mayjen Soetoyo, Cililitan, Jakarta 13640, Indonesia \\ ${ }^{3}$ Cancer Chemoprevention Research Center, Faculty of Pharmacy, Universitas Gadjah Mada, Jalan Sekip Utara, Yogyakarta 55281, \\ Indonesia \\ ${ }^{4}$ Department of Pharmaceutical Chemistry, Faculty of Pharmacy, Universitas Gadjah Mada, Jalan Sekip Utara, Yogyakarta 55281, Indonesia \\ *Corresponding author: meiyan_e@ugm.ac.id
}

SUBMITTED 22 Jun 2018 REVISED 29 Nov 2018 ACCEPTED 22 Dec 2018

\begin{abstract}
Development of a chemotherapeutic agent and boron carrying pharmaceutical based on triple-negative breast cancer is important due to its metastatic progression. Metastases are often more dangerous than the primary tumor and they are responsible for $90 \%$ of all cancer deaths. The purpose of this study was to explore the anti-metastatic activities of the PGB-0 complex with fructose (PGB-0-F) against 4T1 breast cancer cells. A scratch wound healing assay was carried out to determine the migration inhibition ability of PGB-0-F, while MMP-9 expression was analysed using gelatin zymography. The testing of anti-migration activity showed that PGB-0-F inhibited in 4T1 cells, whereas the gelatin zymography assay revealed a suppression of MMP-9 expression. PGB-0-F inhibited closure on 4T1 metastatic breast cancer cells line compared with the control. PGB-0-F decreased the MMP-9 expression level compared with the control. Based on these results, PGB-0-F has the potential to be developed as a chemotherapeutic agent, and especially as an anti-metastatic agent.
\end{abstract}

KEYWORDS 4T1 cells; curcumin analogue; migration; MMP-9; PGB-0-F

\section{Introduction}

Curcumin has shown anti-tumorigenic activity and tumor growth inhibition by increasing ROS levels over the threshold through inhibition of ROS metabolic enzymes. Curcumin has potential in controlling tumor growth by regulating ROS levels in tumor cells (Larasati et al. 2018). However due to its instability, there are several curcumin analogues was developed by modifying the methylene structure with cyclopentanoe such as PGV-0 and PGV1. PGV-0 and PGV-1 showed higher anti-cancer activity compared with curcumin by modulating cell cycle, inducing apoptotic, and inhibiting HER2 and NF-kB activation on MCF-7 and MCF-7/DOX (Da'i et al. 2017; Meiyanto et al. 2014). In addition, K-PGV-0, a soluble form of PGV0 also performed anti-migratory effect on highly metastasis breast cancer (Putri et al. 2016). Dibenzilidine boronic acid cyclopentanone (DBBAC) or pentagamaboronon-0 (PGB-0) is a novel boron containing-curcumin analog which is designed and synthesized by Cancer Chemoprevention Research Center, Universitas Gadjah Mada based on the benzylidine cyclopentanone structure (Utomo et al. 2017). This compound has been explored for the anticancer activity and boron carrying pharmaceutical for BNCT (Boron Neuton Capture Therapy). PGB-0 pos- sessed cytotoxic effect on MCF-7/HER2 cells through decreasing HER2 expression (Utomo et al. 2017). On the other hand, PGB-0 also performed anti-migratory effect against $4 \mathrm{~T} 1$ breast cancer cells by modulating cell cycle, inducing apoptosis, inhibiting migration, and decreasing MMP-9 expression (soon will be publised). However, common curcumin analogues as well as PGB-0 showed poor solubility in water. Therefore several efforts are needed in order to increase the solubility of PGB-0.

One possible strategy to improve the solubility of PGB-0 is through a preparation of a saccharide complex formula. Recent studies have reported a method of solubilizing p-BPA (p-boronophenylalanine), the second generation of boron compounds at a neutral $\mathrm{pH}$ using fructose, to yield a p-BPA-fructose complex. This p-BPA-fructose complex performed better solubility in water compare to free p-BPA (Yoshino et al. 1989). Based on the application of BPA complexation with fructose, CCRC Faculty of Pharmacy Universitas Gadjah Mada synthesized PGB0 -F (Figure 1 ) by complexing PGB-0 with fructose to improve solubility of PGB-0. However, there has been no information related to the activity of PGB-0-F on metastasis of breast cancer cells, especially when the type of cancer is triple-negative breast cancer. In this study we investigated the anti-metastatic activities of PGB-0-F against 
<smiles>O=C1/C(=C/c2ccc(B(O)O)cc2)CC/C1=C\c1ccc(B(O)O)cc1</smiles>

(a)

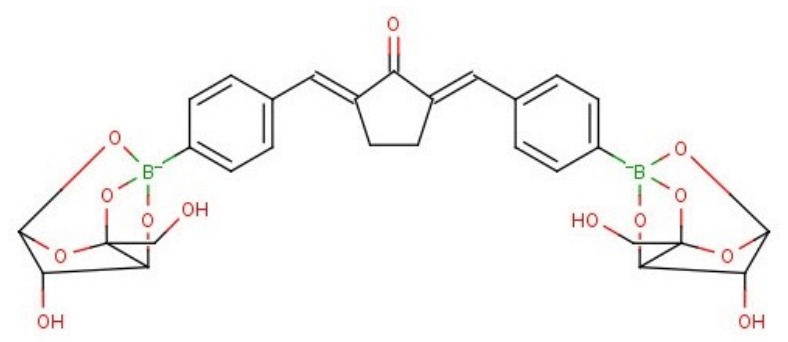

(b)

FIGURE 1 Chemical structure of curcumin analogue compound, BCP: (a) PGB-O (Utomo et al. 2017); (b) PGB-0-F.

highly metastatic breast cancer cells, 4T1. The study was conducted by observing cell migration by scratch wound healing assay and protein activity of MMP-9 by gelatin zymograph. The result of this study will be used for further experiment in order to develop novel anti-metastasis agents from PGB-0-Fructose complex.

\section{Materials and methods}

\subsection{Chemicals}

PGB-0-F was synthetized by Cancer Chemoprevention Research Center, Faculty of Pharmacy, Universitas Gadjah Mada. Doxorubicin was purchased from Sigma.

\subsection{Cell Culture}

Breast cancer cell line culture type 4T1 was obtained from Prof. Masashi Kawaichi, M.D., Ph.D (Nara Institute of Science and Technology, NAIST, Japan). The cells were maintained in Dulbecco’s Modified Eagles Medium (DMEM) high glucose (Sigma) with 10\% FBS (Sigma), HEPES, sodium bicarbonate, $1000 \mathrm{U} / \mathrm{mL}$ of Penicilin$1000 \mathrm{U} / \mathrm{ml}$ of Streptomycin and $0.5 \mu \mathrm{g} / \mathrm{mL}$ Fungizone (Gibco).

\subsection{Scratch wound healing assay}

The 4T1 breast cancer cells were seeded with $7.5 \times 10^{4}$ cells/well density in well-plate and incubated for $24 \mathrm{~h}$ at $37^{\circ} \mathrm{C}$ until reaching confluence of $80 \%$. Medium was removed and cultured cell was washed with $100 \mu \mathrm{L}$ PBS (Sigma). Then, cells were added with medium containing $0.5 \%$ FBS for starvation and being incubated for $22 \mathrm{~h}$. Each well was scratched in the bottom center of the well within cell layer by using yellow tip and treated with Doxorubicin $10 \mathrm{nM}$ as positive control, PGB-0-F, and combination of both compounds. The culture then incubated for $48 \mathrm{~h}$ at $37^{\circ} \mathrm{C}$. The cell migration were documented in 0, 18, 24 and $42 \mathrm{~h}$ under inverted microscope (Olympus) and captured by digital camera (Samsung).

\subsection{Gelatin-zymograph methods}

Gelatin zymography was performed to quantify the matrix metalloproteinase-9 (MMP-9) activity. Briefly, 4T1 cells were culture in 6 -well plates $\left(2 \times 10^{5}\right.$ cells/well) followed by treatment with Doxorubicin $10 \mathrm{nM}, 0,4.25$, 8.5, and $17 \mu \mathrm{M}$ of PGB-0-F, or combination of them in starvation medium for $24 \mathrm{~h}$. After treatment, the supernatant (conditioned medium) for each sample was collected and then separated by $8 \%$ SDS-PAGE supplemented with $0.1 \%$ gelatin. Next, the gel was incubated in $2 \%$ of Triton-X 100 (Merck, New Jersey, USA) in water for $30 \mathrm{~min}$ at room temperature and the gel was then removed from solution. Furthermore incubation buffer, consist of $40 \mathrm{mM}$ Tris-HCl $\mathrm{pH} 8,10 \mathrm{mM} \mathrm{CaCl}_{2}, 0.02 \% \mathrm{NaN}_{3}$, was added to gel and incubated again at $37^{\circ} \mathrm{C}$ for $18-20 \mathrm{~h}$. Then, the gel was stained using Coomassie Brilliant Blue R-250 solution and de-stained until clear bands with blue background were observed. Those bands were documented and analyzed using ImageJ 1.51j8 Java 1.8.0_112 software.

\section{Results}

\subsection{Anti-migratory effect of PGB-0-F on $4 T 1$ cells}

The purpose of this study is to develop PGB-0-F as novel anti-metastasis agents. First, cells migration need to be observed as the initial steps of cells metastasis. Dox at low concentration (10 nM) was used as known chemotherapy that induced migration (Bandyopadhyay et al. 2010). Scratch wound healing assay was conducted to observe cells migration after various concentration under IC 50 value, $1 / 8,1 / 4$, and $1 / 2$ of IC $_{50}$ (Figure 3b). After 42 h observation, Dox increased the \% closure up to $100 \%$ indicating the migratory effect. On the other hand, single treatment of PGB-0-F showed similar profile with untreated cells. Interestingly, combination of Dox with all concentration of PGB-0-F decreased \% closure up to 52$73 \%$. Hence, treatment of PGB-0-F can decrease migration induction by Dox. The result needs to be confirmed with the expression of certain protein played role on cells migration or invasion.

\subsection{Effect of PGB-0-F on MMP-9 expression}

Cancer cells migration and invasion was tightly regulated by certain proteins especially Matrix Metalloproteinase 9 (MMP-9). Role of MMP-9 on cells migration and invasion was to degrade extracellular matrix (ECM) around cancer cells (Reunanen and Kähäri 2013). To observe possible effect of PGB-0-F on decreasing expression of MMP-9, gelatine zymmograph was performed on 4T1 cells. Low concentration of Dox (10 nM) increased MMP-9 expression which confirmed the migratory effect on scratch wound healing assay. In contrast, both single treatment of PGB$0-\mathrm{F}$ and its combination with Dox did not affect MMP-9 expression. Hence, anti-migratory effect of PGB-0-F on Dox induction possibly through other proteins. 


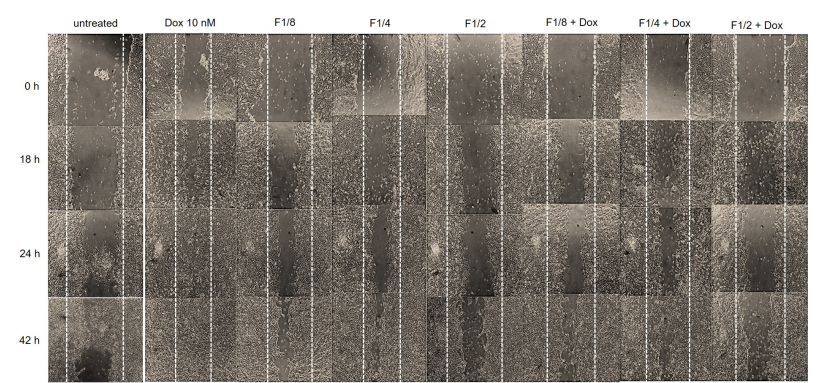

(a)

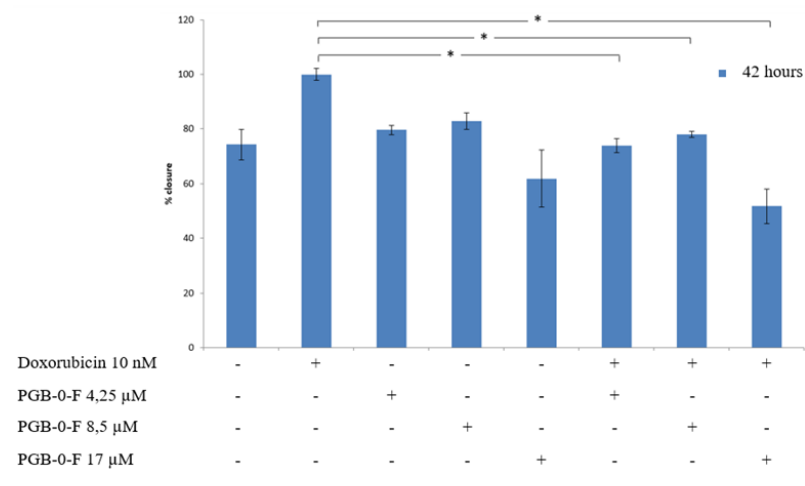

(b)

FIGURE 2 Effect of PGB-0-F on 4T1 Cells Migration. 4T1 cells (7.5 $\times 10^{4}$ cells/well) were treated with PGB-0-F in the concentration as indicated in the figure, then subjected for scratch wound healing assay. (a) The morphology of the cells after scratch and treated with PGB-O-F. Observations were made after 18,24 and $42 \mathrm{~h}$ of treatment under an inverted microscope with magnification of 100x. (b) The percentage of $4 \mathrm{~T} 1$ cells closure after treatment. The area of the scratch was analyzed using Image J then \% closure was calculated in accordance with the procedures of the analysis $(p<0.05)$.

\section{Discussion}

Inhibition of tumor cell migration is crucial in the therapeutic and inhibition of cancer spread, especially in metastasis. Thus, it is necessary to develop anti-metastatic agent. Previous research showed that PGB-0 has anti-migration effect and MMP-9 expression inhibition activity (unpublished data). MMP-9 is a family member of zinc- and calcium-dependent endopeptidases, $92 \mathrm{kDa}$ protein which has numerous cell activities, involving in various physiological functions, such as cell-cell contact, tissue remodeling cell migration and cellular differentiation (Vandooren et al. 2013).

Other study using boron containing compound, phenylboronic acid showed that this compound has potency as selective inhibitor of cancer cell migration and viability without effecting non-tumorigenic cell lines (Bradke et al. 2008; McAuley et al. 2011). The main purpose of this study is to explore the potential metastasis-inhibitory of PGB-0-F on triple-negative breast cancer cells, 4T1. In this study, 4T1 cells were used as the model of human metastatic breast cancer cells because it is highly metastatic breast cancer cells. This cells can metastasize to liver, lung, bone and brain, making it a good model of human metastatic breast cancer (DuPré et al. 2007; Heppner et al. 2000).
MMP-9

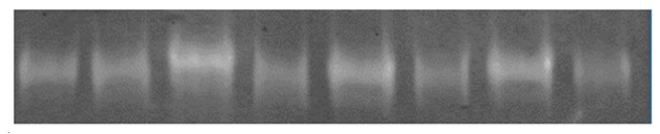

(a)

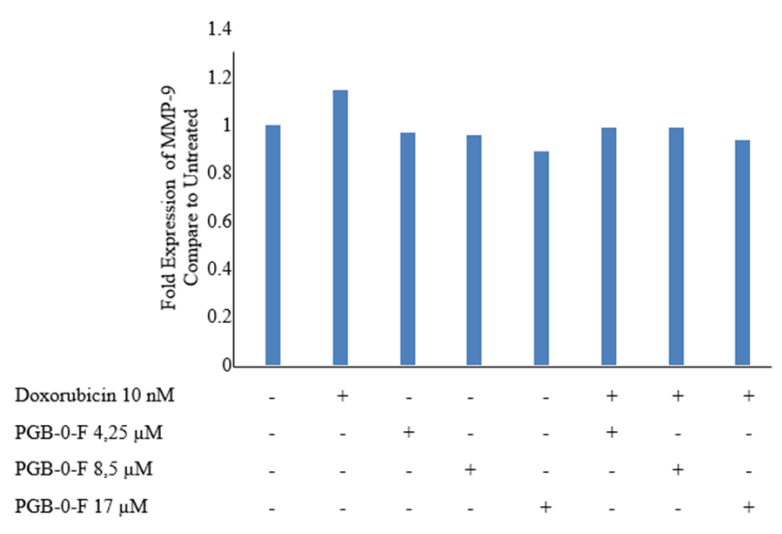

(b)

FIGURE 3 Result of MMP-9 Expression with PGB-0-F and combination with doxorubicin treatment ( $24 \mathrm{~h}$ ): (a) band of MMP-9 Expression; (b) intensity quantification of MMP-9 band.

Doxorubicin is usually used as first-line treatment of several type of cancer especially triple-negative breast cancer. Prolonged use of doxorubicin has a toxicity effect such as cardiotoxicity and hepatotoxicity (Wallace 2003). Other research showed that doxorubicin at low dose can enhanced cancer cell migration by induced lamellipodia formation (Amalina et al. 2017). Previous studies showed the inbitory activity of migration of PGB-0 (Pentagamaboronon-0-frucose) in 4T1 cells (Kusumastuti et al., unpublished data).

Previous study showed that PGB-0-F as an anti-cancer agent which has cytotoxic effect of $4 \mathrm{~T} 1$ cells with $\mathrm{IC}_{50}$ values of $33 \mu \mathrm{M}$ (Meiyanto et al., unpublished data), while PGB-0 has $\mathrm{IC}_{50}$ value of $300 \mu \mathrm{M}$ in $4 \mathrm{~T} 1$ cells (Kusumastuti et al., unpublished data), and $270 \mu \mathrm{M}$ in MCF-7/Her2 cells (Utomo et al. 2017). In this present study, we also observed the inhibition of cancer cell migration as the one of parts of metastasis process by treatment of PGB-0-F through scratch wound healing assay. Cell migration is part of the metastasis process. Based on the percent graph of $4 \mathrm{~T} 1$ cell closure (Figure 3a) the treatment of PGB-0-F with concentration of 4.25 and $8.5 \mu \mathrm{M}$ have not demonstrated any migration inhibitory activity in all time course but enhanced migration of 4T1 cell by showing a \% closure profile of the cell similar to cell control's (untreated). In the PGB-0-F concentration of $17 \mu \mathrm{M}$, 4T1 cells began to effect inhibition of cell migration in $42^{\text {nd }}$ hour, but no significant effect in $18^{\text {th }}$ and $24^{\text {th }}$ hour.

The treatment of doxorubicin $10 \mathrm{nM}$ showed higher $\%$ closure than untreated cells, it means that doxorubicin induced cell migration. Previous result that doxorubicin induced lamelipodia formation and cell migration in 4T1 and MCF-7/Her2 cells (Amalina et al. 2017). Furthermore, combination treatment of PGB-0-F and doxorubicin 
showed inhibition of $4 \mathrm{~T} 1$ cell migration in $42 \mathrm{~h}$ incubation time. At this incubation time both single PGB-0-F 1/2 $\mathrm{IC}_{50}$ treatment and its combination with $10 \mathrm{nM}$ doxorubicin showed significant differences with the difference in percentage closing percentages with consecutive values of $12 \%$ and $22 \%$, respectively, compared with the control of cells without treatment. Whereas when PGB-0-F treatment with doxorubicin $10 \mathrm{nM}$ compared with a single treatment doxorubicin $10 \mathrm{nM}$ resulted in a closing percentage percentage of $48 \%$. Overall, PGB-0-F treatment in three doses, $1 / 8,1 / 4$, and $1 / 2 \mathrm{IC}_{50}$.

Since in the breast cancer patients there is a significant association between high MMP9 expression and poor survival (Song et al. 2013), therefore the MMP-9 expression would be a potential therapeutic target to inhibit the development of cancer metastasis. Curcumin analogue PGB-0-F showed tendency of inhibitory effect of MMP9 expression in gelatin zymograph assay in $24 \mathrm{~h}$ treatment. Previous study showed that PGB-0 also showed the inhibition effect of MMP-9 expression (to be published elsewhere). Curcumin itself showed the inhibition of MMP9 expression by inhibiting MAPKs phosphorylation (Cao et al. 2014). Other research showed that simultaneous silencing of MMP9 in breast cancer cells decreased the wound healing, migratory, invasive and adhesive capacity of the cells by increasing cell-cell adhesion and modulating EMT (Epithelial-to-Mesenchymal Transition) genes (Moirangthem et al. 2016).

\section{Conclusions}

PGB-0-F exhibits anti-migration effect against doxorubicin treatment cells. PGB-0-F also inhibits MMP-9 expression which may have the potential to inhibit tumor invasion.

\section{Acknowledgments}

Our thanks are to LPDP (Indonesia Endowment Fund for Education), Ministry of Finance, Republic of Indonesia and CCRC (Cancer Chemoprevention Research Center) which has funded this research.

\section{Authors' contributions}

YE performed most the experiment, data collection, statistical analysis, and drafted the manuscript; RYU conducted PGB-0-F synthesis experiment; RIJ supervised the in vitro experiment; RAS supervised the PGB-0-F synthesis experiment; EM designed and supervised all of the experiment and prepared the paper.

\section{Competing interests}

The authors declare that they have no competing interests.

\section{References}

Amalina ND, Nurhayati IP, Meiyanto E. 2017. Doxorubicin induces lamellipodia formation and cell migra- tion. Indones J Cancer Chemoprev. 8(2):61-67. doi: 10.14499/indonesianjcanchemoprev8iss2pp61-67.

Bandyopadhyay A, Wang L, Agyin J, Tang Y, Lin S, Yeh IT, De K, Sun LZ. 2010. Doxorubicin in combination with a small TGF $\beta$ inhibitor: a potential novel therapy for metastatic breast cancer in mouse models. PLoS ONE. 5(4):e10365. doi:10.1371/journal.pone. 0010365.

Bradke TM, Hall C, Carper SW, Plopper GE. 2008. Phenylboronic acid selectively inhibits human prostate and breast cancer cell migration and decreases viability. Cell Adhes Migr. 2(3):153-160. doi:10.4161/cam.2.3.6484.

Cao J, Han Z, Tian L, Chen K, Fan Y, Ye B, Huang W, Wang C, Huang Z. 2014. Curcumin inhibits EMMPRIN and MMP-9 expression through AMPK-MAPK and PKC signaling in PMA induced macrophages. J Transl Med. 12(1):266. doi:10.1186/ s12967-014-0266-2.

Da’i M, Suhendi A, Meiyanto E, Jenie UA, Kawaichi M. 2017. Apoptosis induction effect of curcumin and its analogs pentagamavunon- 0 and pentagamavunon -1 on cancer cell lines. Asian J Pharm Clin Res. 10(3):373-376. doi:10.22159/ajpcr.2017.v10i3. 16311.

DuPré SA, Redelman D, Hunter Jr KW. 2007. The mouse mammary carcinoma 4T1: characterization of the cellular landscape of primary tumours and metastatic tumour foci. Int J Exp Pathol. 88(5):351-360. doi: 10.1111/j.1365-2613.2007.00539.x.

Heppner GH, Miller FR, Shekhar PM. 2000. Nontransgenic models of breast cancer. Breast Cancer Res. 2(5):331. doi:10.1186/bcr77.

Larasati YA, Yoneda-Kato N, Nakamae I, Yokoyama T, Meiyanto E, Kato Jy. 2018. Curcumin targets multiple enzymes involved in the ROS metabolic pathway to suppress tumor cell growth. Sci Rep. 8(1):2039. doi: 10.1038/s41598-018-20179-6.

McAuley EM, Bradke TA, Plopper GE. 2011. Phenylboronic acid is a more potent inhibitor than boric acid of key signaling networks involved in cancer cell migration. Cell Adhes Migr. 5(5):382-386. doi:10.4161/ cam.5.5.18162.

Meiyanto E, Putri D, Susidarti RA, Murwanti R, Sardjiman FA, Husnaa U, Purnomo H, Kawaichi M. 2014. Curcumin and its analogues (PGV-0 and PGV-1) enhance sensitivity of resistant MCF-7 cells to doxorubicin through inhibition of HER2 and NF-kB activation. Asian Pac J Cancer Prev. 15(1):179-184. doi: 10.7314/арjср.2014.15.1.179.

Moirangthem A, Bondhopadhyay B, Mukherjee M, Bandyopadhyay A, Mukherjee N, Konar K, Bhattacharya S, Basu A. 2016. Simultaneous knockdown of upa and mmp9 can reduce breast cancer progression by increasing cell-cell adhesion and modulating emt genes. Scientific reports. 6:21903. doi:10.1038/ srep21903.

Putri H, Jenie RI, Handayani S, Kastian RF, Meiyanto E. 
2016. Combination of potassium pentagamavunon0 and doxorubicin induces apoptosis and cell cycle arrest and inhibits metastasis in breast cancer cells. Asian Pac J Cancer Prev. 17(5):2683-2688.

Reunanen N, Kähäri V. 2013. Matrix metalloproteinases in cancer cell invasion. Austin [TX]: Landes Bioscience.

Song J, Su H, Zhou YY, Guo LL. 2013. Prognostic value of matrix metalloproteinase 9 expression in breast cancer patients: a meta-analysis. Asian Pac J Cancer Prev. 14(3):1615-1621. doi:10.7314/apjcp.2013.14.3.1615.

Utomo RY, Putri H, Pudjono P, Susidarti RA, Jenie RI, Meiyanto E. 2017. Synthesis and cytotoxic activity of 2, 5-bis (4-boronic acid) benzylidine cyclopentanone on HER2 overexpressed-cancer cells. Indones J Pharm. 28(2):74. doi:10.14499/ indonesianjpharm28iss2pp74.

Vandooren J, Van den Steen PE, Opdenakker G. 2013. Biochemistry and molecular biology of gelatinase B or matrix metalloproteinase-9 (MMP-9): the next decade. Crit Rev Biochem Mol Biol. 48(3):222-272. doi:10.3109/10409238.2013.770819.

Wallace KB. 2003. Doxorubicin-induced cardiac mitochondrionopathy. Pharmacol Toxicol. 93(3):105-115. doi:10.1034/j.1600-0773.2003.930301.x.

Yoshino K, Suzuki A, Mori Y, Kakihana H, Honda C, Mishima Y, Kobayashi T, Kanda K. 1989. Improvement of solubility of p-boronophenylalanine by complex formation with monosaccharides. Strahlenther Onkol. 165(2-3):127-129. 